\section{Claudia Brito}

Margareth Crisóstomo Portela"

Mauricio Teixeira Leite de

Vasconcellos ${ }^{\text {III }}$
Programa Pós-Graduação em Saúde Pública. Fundação Oswaldo Cruz. Escola Nacional de Saúde Pública Sergio Arouca. Rio de Janeiro, RJ, Brasil

" Departamento de Administração e Planejamento em Saúde. Fundação Oswaldo Cruz. Escola Nacional de Saúde Pública Sergio Arouca. Rio de Janeiro, RJ Brasil

III Escola Nacional de Ciências Estatísticas. Instituto Brasileiro de Geografia e Estatística. Rio de Janeiro, RJ, Brasil

\author{
Correspondence: \\ Claudia Brito \\ Av. Leopoldo Bulhões, 1480/ Sala 724 - \\ Manguinhos \\ 21041-210 Rio de Janeiro, RJ, Brasil \\ E-mail: cbrito@ensp.fiocruz.br
}

\section{Survival of breast cancer women in the state of Rio de Janeiro, Southeastern Brazil}

\begin{abstract}
OBJECTIVE: To assess the association between breast cancer survival and infrastructure and practices of cancer care units.

METHODS: Retrospective longitudinal study based on data from the Brazilian information system of authorizations for highly complex cancer procedures covered by the National Health System and a sample of 310 medical records of prevalent breast cancer cases attended at 15 inpatient and outpatient cancer care units providing chemotherapy between 1999 and 2002 in the state of Rio de Janeiro, Southeastern Brazil. Independent variables were infrastructure of cancer units, interventions, and sociodemographic and clinical characteristics of women. Kaplan-Meier method and Cox proportional hazards model (pseudolikelihood) were used for data analysis.
\end{abstract}

RESULTS: Kaplan-Meier analyses pointed out significant associations between survival and time between diagnosis and treatment start, surgery, hormone therapy, type of adjuvant hormone therapy, therapy combinations, type of care unit and health insurance, unit size and category. Estimates obtained from the Cox model showed positive associations between hazard of death and time between diagnosis and treatment, unit size and type combined to use of health insurance, and negative associations between survival and surgery and type of hormone therapy.

CONCLUSIONS: The study findings show an association between breast cancer survival and health care provided by affiliated services with practical implications for policy making for cancer control in Brazil.

\section{DESCRIPTORS: Breast Neoplasms, Survival Analysis , Outcome and Process Assessment (Health Care), Supplemental Health, Health Public Policy.}

\section{INTRODUCTION}

Breast cancer is the leading cause of death due to cancer in women in Brazil since 1979 and time series analyses have showed it has worsened. ${ }^{a}$ Mortality trend is a major indicator that can measure improvement of cancer care as it captures the effects of prevention, screening, and treatment. ${ }^{9}$ In $2008,49,400$ new cases of breast cancer were expected with an estimated risk of 51 cases per 100,000 women. $^{b}$

\footnotetext{
a Ministério da Saúde. Instituto Nacional do Câncer. Estimativas da incidência e mortalidade por câncer no Brasil 2002. Rio de Janeiro; 2003

${ }^{\mathrm{b}}$ Ministério da Saúde. Instituto Nacional do Câncer. Estimativa 2008: incidência de câncer no Brasil. Rio de Janeiro; 2007.
} 
In addition to its epidemiological relevance, breast cancer in Brazil represents a challenge to the National Health System (Sistema Único de Saúde - SUS) due to demands of increasingly complex and costly care services, huge pressure for the inclusion of new technologies, and unawareness of the quality of services provided. Since cancer mortality is determined not only by clinical and socioeconomic factors but also by the availability and quality of care provided, studies assessing care may provide input for improving care-related indicators. To that effect survival is a common measure that can provide information on disease staging (based on screening methods), care availability and access, and treatment effectiveness, among others. There are three main sources of information: clinical trials that evaluate treatment options; population-based studies that examine outreach of cancer control activities; and hospital-based studies that can provide information on treatment outcomes under specific conditions. ${ }^{17}$

The objective of the present study was to assess the association between breast cancer survival and infrastructure and practices in cancer care units.

\section{METHODS}

A longitudinal retrospective study was conducted in a sample of breast cancer women attended at SUS services in the state of Rio de Janeiro.

For sample selection an exploratory assessment of the Information System of Authorizations for Highly Complex Cancer Procedures (SIA/APAC-ONCO) was first carried out. Based on SIA/APAC-ONCO data, a listing was compiled including 10,862 breast cancer women who underwent chemotherapy (and hormone therapy) in at least one of 15 SUS-contracted units in the state of Rio de Janeiro between November 1999 and November 2002 (Table 1). Of all breast cancer patients identified in the database, there were excluded men, women with procedure codes not consistent with the diagnosis under study, and those women seen at non-contracted care units during the study period. Those women who received treatment in more than one unit were linked to that unit where they received longer care; when they received care for the same amount of time at different units, the last unit attended was considered in the analysis. This procedure was intended to avoid any effect on the likelihood of sample selection by including the same patient at different care units who care was sought.

A random sample of 310 medical records was systematically selected from the listing. The sample size was estimated to provide mean age of patients at the time of diagnosis with a $2.5 \%$ relative error at a $5 \%$ significance level. Sorting the listing by type of contracted cancer unit (High Complexity Cancer Center $[\mathrm{CACON}]$ or low complexity single care unit), age group at diagnosis, associated to a systematic selection method, was consistent with an implicit population stratification which ensured representativeness of all population segments.

Searching medical records was required since APACONCO system reliability was unknown and it did not provide all information relevant to the study. Therefore, all information on interventions and patient demographics were obtained from medical records.

Of all medical records selected to the sample, no replacements were required due to losses. But there were three instances of record replacement: one due to misinformation on gender (a male patient recorded as female) and two due to missing information ascertaining patient care at the unit although it was billed to SUS.

The dependent variable was survival of breast cancer patients assuming that it reflects factors associated to screening, care availability and access, and treatment effectiveness.

For survival estimate, time between the first consultation and death due to breast cancer (failed) or last consultation recorded (censored) was estimated. Censored cases were those women who were still attending care at the end of the study period as well as those lost to follow-up due to treatment withdrawal or transfer to a different care unit during the study or even due to death caused by other non-related causes.

Independent variables were factors related to care unit infrastructure, and interventions, and sociodemographic and clinical characteristics of women were considered for risk control in the study.

Variables related to cancer unit infrastructure were: (1) type of cancer unit: low-complexity single (an outpatient unit that provides radiotherapy and/or chemotherapy only), or CACON (a hospital unit with all resources within the same structure for providing treatment to the most common cancers in Brazil); (2) specifically for single units, information on coverage or not by private insurance was added; (3) service category: public, private, or charitable; (4) service size: small, medium, or large; and (5) unit location: capital or interior.

Intervention-related variables included: (1) time from diagnosis to treatment start ( $<6$ months; or $\geq 6$ months); (2) hormone therapy (yes or no); (3) type of hormone therapy (first-line, second-line, or no specific line); (4) surgery (yes or no); (5) radiotherapy (yes or no), and; (6) combination therapy (single or combined use of therapies - surgery, chemotherapy, hormone therapy, and radiotherapy). SUS classifies hormone therapy as first-line, second-line, and no specific line of therapy. First-line and no specific line of therapy include tamoxifen for palliative care and adjuvant therapy, respectively. Second-line therapy includes aromatase inhibitor for both adjuvant and palliative care. 
Sociodemographic variables were: (1) age at diagnosis and age at treatment start (less than 35, 35-69, 70 or more), and; (2) area service (availability or not of contracted cancer services in the city where the patient lived).

Prognostic clinical factors were: (1) staging (I, II, III or IV); (2) histological classification of tumors (GI [well differentiated], GII [moderately differentiated] or GIII [poorly differentiated]), and; (3) response to estrogen (ER) and progesterone (PR) hormone receptors (positive or negative).

To capture differences between prevalent and incident cases, two variables were created: (1) treatment start (pre- or post-November 1999) and; (2) time between treatment start and study enrollment (in months).

The Kaplan-Meier method was performed, considering patient follow-up time from November 1999, to determine overall survival time, and survival stratified by independent variables. The Wilcoxon test was applied to compare survival curves between different strata, given its greater sensitivity to differences seen at more remote time points. ${ }^{10}$

To describe the independent effect of survival explanatory variables a multivariate Cox proportional hazards model (hazard ratio, HR) was created assuming a 5\% significance level. The assumption of proportional hazards was tested by adding interaction terms of explanatory variables with time, which were not statistically significant.

Since SIA/APAC-ONCO database included prevalent and incident breast cancer cases - those women who died before November 1999 when APAC-ONCO was implemented did not have a chance of being selected to the sample and to participate in the study-, it was opted in the analysis of Cox model for a count process associated to regression estimation of maximum pseudo-likelihood of survival. ${ }^{5,16}$ The final model included only borderline or statistically significant variables $(\alpha=0.05)$.

All analyses were carried out using SAS, version 9.0.

The study was approved by the Research Ethics Committee of Escola Nacional de Sáude Pública/Fundação Oswaldo Cruz (ENSP/FIOCRUZ) and Clinical Trial Scientific Board and Institutional Review Board of the Instituto Nacional do Câncer.

\section{RESULTS}

Significant differences were found between occurrence of death and continuous variables such as age at treatment start and age at diagnosis and time between diagnosis and treatment start among those who died and survived at the end of the follow-up period.
Those who died were younger at treatment start and at diagnosis and showed greater mean time between diagnosis and treatment start.

Significant differences were found in survival curves in the different categories of independent variables (Tables 2 and 3): type of unit plus health insurance; service category; service size; unit location; time between diagnosis and treatment start ( $<6$ months; or $\geq 6$ months); type of hormone therapy; surgery; combination therapy; age at treatment start, age at diagnosis, cancer staging; histological grade; and hormone receptor. No significant differences were found in survival curves of women living in cities with and without cancer services available; women exposed and non-exposed to radiotherapy; and women who started treatment pre- and post-November 1999.

As for variables related to service infrastructure or care process, Table 2 shows that conditional probabilities of survival were lower in uninsured women cared at single units, charitable services, small size services or those located in the interior, cases with longer time between diagnosis and treatment start ( $>6$ months), second-line hormone therapy, women who did not undergo breast cancer surgery and when treatment plan included chemotherapy only (not including hormone therapy).

Table 3 shows survival curves with a sharper fall in younger women at diagnosis (less than 35), with

Table 1. Distribution of the study sample by contracted unit, type of unit, and city. State of Rio de Janeiro, Southeastern Brazil, 1999-2002.

\begin{tabular}{lccc}
\hline City & $\begin{array}{c}\text { Type of } \\
\text { unit }\end{array}$ & $\begin{array}{c}\text { Number of } \\
\text { patients listed }\end{array}$ & $\begin{array}{c}\text { Sample } \\
\text { size }\end{array}$ \\
\hline Campos & single unit & 439 & 12 \\
Campos & CACON & 182 & 5 \\
Itaperuna & CACON & 117 & 4 \\
Magé & single unit & 30 & 1 \\
Mesquita & single unit & 162 & 5 \\
Niterói & CACON & 31 & 1 \\
Nova lguaçu & single unit & 396 & 11 \\
Petrópolis & single unit & 462 & 13 \\
Rio de Janeiro & CACON & 7,318 & 209 \\
Rio de Janeiro & CACON & 541 & 15 \\
Rio de Janeiro & CACON & 99 & 3 \\
Rio de Janeiro & CACON & 459 & 13 \\
Rio de Janeiro & CACON & 81 & 2 \\
Teresópolis & single unit & 111 & 3 \\
Volta Redonda & single unit & 434 & 13 \\
\hline Total & & 10,862 & 310 \\
\hline
\end{tabular}

Source: Information System of Authorizations for Highly Complex Cancer Procedures - Chemotherapy;

CACON - High Complexity Cancer Center 
Table 2. Kaplan-Meier analysis comparing breast cancer survival by service-related variables $(\mathrm{n}=310)$. State of Rio de Janeiro, Southeastern Brazil, 1999-2002.

\begin{tabular}{|c|c|c|c|}
\hline Variable & $\mathrm{n}$ & Women alive at the end of the study (\%) & p-value \\
\hline Type of unit & & & 0.0929 \\
\hline CACON & 252 & 73.0 & \\
\hline Single & 58 & 68.9 & \\
\hline Type of unit and health insurance & & & 0.0193 \\
\hline CACON & 252 & 73.0 & \\
\hline Single and insured & 17 & 82.3 & \\
\hline Single and uninsured & 41 & 63.4 & \\
\hline Service category & & & 0.0356 \\
\hline Charitable & 22 & 68.2 & \\
\hline Public & 228 & 73.2 & \\
\hline Private & 60 & 70.0 & \\
\hline Service size & & & 0.0073 \\
\hline Large & 209 & 74.2 & \\
\hline Medium & 77 & 71.4 & \\
\hline Small & 24 & 58.3 & \\
\hline Unit location & & & 0.0177 \\
\hline Capital & 242 & 73.5 & \\
\hline Interior & 68 & 67.6 & \\
\hline Time between diagnosis and treatment start & & & $<0.0001$ \\
\hline$<6$ months & 284 & 74.6 & \\
\hline$\geq 6$ months & 26 & 46.1 & \\
\hline Hormone therapy & & & $<0.0001$ \\
\hline No hormone therapy & 82 & 59.8 & \\
\hline First-line therapy & 34 & 44.1 & \\
\hline Second-line therapy & 22 & 31.8 & \\
\hline No specific line of therapy & 172 & 88.9 & \\
\hline Surgery & & & $<0.0001$ \\
\hline Yes & 262 & 78.2 & \\
\hline No & 48 & 39.6 & \\
\hline Radiotherapy & & & 0.3298 \\
\hline Yes & 204 & 69.1 & \\
\hline No & 38 & 84.2 & \\
\hline Unknown & 68 & 75.0 & \\
\hline Combined therapy & & & $<0.0001$ \\
\hline Dual SUR (SUR+RT; SUR+HT) & 97 & 77.3 & \\
\hline Dual no SUR (RT + HT) & 17 & 41.2 & \\
\hline Monotherapy (SUR or RT or HT) & 49 & 61.2 & \\
\hline Chemotherapy only (no HT) & 8 & 37.5 & \\
\hline All $(S U R+R T+H T)$ & 139 & 78.4 & \\
\hline Treatment start & & & 0.7863 \\
\hline Pre-November 99 & 150 & 65.3 & \\
\hline Post-November 99 (incident) & 160 & 78.7 & \\
\hline
\end{tabular}

SUR: surgery; RT: radiotherapy; HT: hormone therapy

higher staging (III and mostly IV), high or unknown histological grade (G3) and negative or unknown hormone receptor.
The results of Cox regression analysis are presented in Table 4 with non-adjusted and adjusted estimates for explanatory variables. In the multivariate model, hazard 
Table 3. Kaplan-Meier analysis comparing breast cancer survival by clinical and demographic variables $(n=310)$. State of Rio de Janeiro, Southeastern Brazil, 1999-2002.

\begin{tabular}{|c|c|c|c|}
\hline Variable & $\mathrm{n}$ & Women alive at the end of the study (\%) & p-value \\
\hline City of residence & & & 0.7230 \\
\hline No cancer service available & 98 & 70.4 & \\
\hline Cancer service available & 212 & 73.1 & \\
\hline Age at treatment start (years old) & & & 0.0101 \\
\hline Less than 35 & 11 & 45.4 & \\
\hline 35 or more and less than 70 & 244 & 71.3 & \\
\hline 70 or more & 55 & 81.8 & \\
\hline Age at diagnosis (years) & & & 0.0001 \\
\hline Less than 35 & 13 & 38.5 & \\
\hline 35 or more and less than 70 & 243 & 72.0 & \\
\hline 70 or more & 54 & 81.5 & \\
\hline Staging & & & $<0.0001$ \\
\hline I & 27 & 96.3 & \\
\hline II & 123 & 86.2 & \\
\hline III & 98 & 64.3 & \\
\hline IV & 38 & 21.0 & \\
\hline Unknown & 24 & 87.5 & \\
\hline Histopathology grade & & & 0.0041 \\
\hline Well-differentiated (G1) & 13 & 92.3 & \\
\hline Moderately differentiated (G2) & 122 & 78.7 & \\
\hline Poorly differentiated (G3) & 50 & 70.0 & \\
\hline Unknown & 125 & 64.8 & \\
\hline Hormone receptor & & & $<0.0001$ \\
\hline Positive & 177 & 83.6 & \\
\hline Negative & 43 & 69.8 & \\
\hline Unknown & 90 & 51.1 & \\
\hline
\end{tabular}

rate (instantaneous risk of death) was $212.9 \%$ higher in breast cancer women showing time between diagnosis and treatment start greater than six months $(p=0.0005)$; $286.1 \%$ higher among women with tumor staging III or IV ( $<<0.0001) ; 86.3 \%$ higher among those women with histological grade 3 ( $p=0.0514) ; 167.4 \%$ and $91.0 \%$ higher in those women cared at small size $(\mathrm{p}=0.0188)$ and medium-size units ( $\mathrm{p}=0.0395)$; and $104.9 \%$ higher in those uninsured seen at single units $(p=0.0542)$.

In contrast, hazard rate was $55.2 \%$ lower among patients undergoing breast surgery $(\mathrm{p}=0.0043)$, and $71.5 \%$ lower in those receiving hormone therapy of no specific line $(\mathrm{p}<0.0001)$.

In this prevalent cohort, the finding of no statistical significance for the variable time between treatment start and study enrollment (November 1st, 1999), though indicating a protection trend for "survivors," shows that hazard rate among survivors was not statistically different from that of incident cases.

\section{DISCUSSION}

The present study showed prognosis factors for breast cancer consistent with those described in the literature. ${ }^{6,11,14, a}$ Better survival rates are associated to tumor staging I, histological grade 1, and positive hormone receptors.

The Kaplan-Meier analysis showed higher probability of survival in women aged 70 or more at diagnosis or at treatment start and lower probability of survival in women younger than 35 . These results are contrasted ${ }^{4,14}$ and corroborated, ${ }^{6,14}$, respectively, in the literature. Cox's model, however, did not corroborate the notion of an independent effect of age when the remaining variables were controlled for.

a National Comprehensive Cancer Network. NNCN Clinical Practice Guidelines in Oncology: breast cancer. Versão 2, 2008 [internet]. [citado 2008 fev 25]. Disponível em: http://www.nccn.org/professionals/physician_gls/PDF/breast.pdf 
Table 4. Cox regression model for breast cancer survival analysis $(\mathrm{n}=310)$. State of Rio de Janeiro, Southeastern Brazil, 1999-2002.

\begin{tabular}{|c|c|c|c|c|}
\hline \multirow{2}{*}{ Variable } & \multicolumn{2}{|c|}{ Non-adjusted hazard ratio } & \multicolumn{2}{|c|}{ Adjusted hazard ratio } \\
\hline & Estimate & $95 \% \mathrm{Cl}$ & Estimate & $95 \% \mathrm{Cl}$ \\
\hline Time between treatment start and study enrollment (months) & 0.97 & $0.72 ; 1.31$ & 0.79 & $0.57 ; 1.08$ \\
\hline \multicolumn{5}{|l|}{ Time between diagnosis and treatment start } \\
\hline$<6$ months & 2.63 & $1.46 ; 4.75$ & 3.13 & $1.65 ; 5.95$ \\
\hline$\geq 6$ months & 1.00 & & 1.00 & \\
\hline \multicolumn{5}{|l|}{ Staging } \\
\hline III and IV (not curable) & 5.93 & $3.51 ; 10.02$ & 3.86 & $2.14 ; 6.95$ \\
\hline I, II and unknown (ref) & 1.00 & & 1.00 & \\
\hline \multicolumn{5}{|l|}{ Histopathology grade } \\
\hline G3 (high) & 1.17 & $0.67 ; 2.06$ & 1.86 & $0.10 ; 3.49$ \\
\hline G1, G2 and unknown (ref) & 1.00 & & 1.00 & \\
\hline \multicolumn{5}{|l|}{ Surgery } \\
\hline Yes & 0.21 & $0.13 ; 0.33$ & 0.45 & $0.26 ; 0.78$ \\
\hline No (ref) & 1.00 & & 1.00 & \\
\hline \multicolumn{5}{|l|}{ Hormone therapy } \\
\hline No specific line & 0.16 & $0.10 ; 0.27$ & 0.29 & $0.16 ; 0.51$ \\
\hline First, second, and no therapy (ref) & 1.00 & & 1.00 & \\
\hline \multicolumn{5}{|l|}{ Service size } \\
\hline Small & 1.87 & $0.96 ; 3.63$ & 2.67 & $1.18 ; 6.08$ \\
\hline Medium & 1.38 & $0.85 ; 2.25$ & 1.91 & $1.03 ; 3.54$ \\
\hline Large (ref) & 1.00 & & 1.00 & \\
\hline \multicolumn{5}{|l|}{ Type of unit and health insurance } \\
\hline Single unit and insured & 1.97 & $1.12 ; 3.47$ & 2.05 & $0.99 ; 4.25$ \\
\hline CACON and single unit and insured (ref) & 1.00 & & 1.00 & \\
\hline
\end{tabular}

Ref: reference

Disease staging at diagnosis is often a major factor determining survival of cancer patients because some treatments are only indicated for tumors at an early stage and are more effective if started before tumor metastasis. ${ }^{3}$ The findings of the present study ascertain the well-known inverse relationship between survival rate and cancer staging at diagnosis. ${ }^{8}$

In regard to factors related to the infrastructure of care units studied, there remained independently associated to lower instantaneous risk of death in the Cox model the variables indicative of insured care in single units and, implicitly, care at large-size units. These findings are corroborated in the literature, which reported longer survival of cancer patients treated in large reference centers ${ }^{1,9,12}$ and in those patients with coverage of health insurance. ${ }^{2}$ The literature also reports more favorable outcomes in better-off areas with better socioeconomic conditions, which supports the trend observed of longer survival in capital services. ${ }^{7,15}$

In the present study, due to specific characteristics of cancer care in the state of Rio de Janeiro, variables such as type of unit, service category and location are strongly correlated because they represent, hegemonically, similar characteristics.

The analysis of treatment regimens showed better outcomes among women receiving hormone therapy, surgery, and radiotherapy, followed by those undergoing surgery plus any combined therapy (surgery plus hormone therapy; surgery plus radiotherapy). Nonhormone chemotherapy was the single strategy with the worst outcome.

Surgery was particularly a determinant of survival in all prevalent cases, both for surgery only and for combined therapy. The same was reported by Rao et $\mathrm{al}^{13}$ while studying women over 80 , supporting the current protocols and recommendations made by authorities of best practices in health.

The finding of lower risk of death in patients who started treatment earlier (less than 6 months after diagnosis) also corroborates what it was expected and the literature, showing better survival rates associated to early diagnosis and timely and adequate treatment., ${ }^{917}$ 
To investigate the effects of treatment-associated results, a randomized clinical trial is a powerful design as it reduces bias effects and can establish a close relationship between cause and effect. However, some aspects of care affecting its results cannot be assessed through randomized clinical trials. Observational studies are a practical and feasible approach. In addition, the overall effectiveness of services is not determined only by the efficacy of a given treatment but also the context where treatment is provided. ${ }^{3}$

Since the purpose was to assess care provided in cancer units based on data from patients attending these services, patients who were already receiving treatment (prevalent cases) were not excluded form the analysis. While this choice allowed a more thorough assessment of patients under treatment and, therefore, of services provided, it required more complex statistical analyses, mostly the replacement of a priori probabilities of survival with probabilities conditioned to the assumption that patients were alive at the beginning of the study period.

In conclusion, the study results showed there are differences in the probability of breast cancer survival associated to the characteristics of care units and interventions provided, regardless of the effect of patient clinical characteristics. These results are expected to help develop cancer care practices in the state of Rio de Janeiro and formulate policies for cancer control in Brazil. The current Decree that regulates SUS contracting of cancer services prioritizes comprehensive care to cancer patients and thus single units are no longer contracted for cancer treatment. Hopefully this regulation will be actually put into effect.

\footnotetext{
a Ministério da Saúde. Portaria n 741, de 19 de dezembro de 2005. Define as unidades de assistência de alta complexidade em oncologia os centros de assistência de alta complexidade em oncologia (CACON) e os centros de referência de alta complexidade em oncologia e suas aptidões e qualidades. Diário Oficial União. 23 dez 2005.
} 


\section{REFERENCES}

1. Adams RD, Johansen KL, Brand R, Rennie DJ Milstein A. Selective referral to high-volume hospitals: estimating potentially avoidable deaths. JAMA. 2000;283(9):1159-66. DOI: 10.1001/jama.283.9.1159

2. Ayanian JZ, Kohler BA, Abe T, Epstein AM. The relation between health insurance coverage and clinical outcomes among women with breast cancer. N Engl / Med. 1993;329(5):326-31. DOI: 10.1056/ NEJM199307293290507

3. Black RJ, Sankaranarayanan R, Parkin D M. Interpretation of population-based cancer survival data. In: Sankaranarayanan R, Black RJ, Parkin DM editors. Cancer survival in developing countries. Lyon: WHO; 1998. p.13-7. (IARC Scientific Publications, 145)

4. Chia KS, Du WB, Sankaranarayanan R, Sankila R, Wang $\mathrm{H}$, Lee J, et al. Do younger female breast cancer patients have a poorer prognosis? Results from a population-based survival analysis. Int J Cancer. 2004;108(5):761-5. DOI: 10.1002/ijc.11632

5. Copas AJ, Farewell V. Incorporating retrospective data into an analysis of time to illness. Biostatistics, 2001;2(1):1-12. DOI: 10.1093/biostatistics/2.1.1

6. Goldhirsch A, Glick JH, Gelber RD, Coates AS, Thürlimann B, Senn HJ. Meeting highlights: international expert consensus on the primary therapy of early breast cancer 2005. Ann Oncol. 2005;16(10):1569-83. DOI: 10.1093/annonc/mdi326

7. Halmin M, Bellocco R, Lagerlund M, Karlsson P, Tejler G, Lambe M. Long-term inequalities in breast cancer survival - a ten year follow-up study of patients managed within a National Health Care System (Sweden). Acta Oncol. 2008;47(2):216-24. DOI: 10.1080/02841860701769768

8. Henson DE, Ries LA, Carriaga MT. Conditional survival of 56.268 patients with breast cancer. Cancer. 1995;76(2):237-42. DOI:
10.1002/1097-0142(19950715)76:2<237::AIDCNCR2820760213>3.0.CO;2-J

9. Hewitt M, Simone JV, editors. Ensuring quality to cancer care. Washington, DC: National Academy Press; 1999.

10. Kleinbaum DG. Survival analysis: a self-learning text. New York: Spriger; 1995.

11. Marrazzoa A, Taormina P, David M, Riili I, Casà L, Catalano F, et al. Survival of breast cancer patients. Our experience. Chir Ital. 2007;59(3):313-8.

12. Nomura E, Tsukuma H, Ajiki W, Ishikawa O, Oshima A.Population-based study of the relationship between hospital surgical volume and 10-year survival of breast cancer patients in Osaka, Japan. Cancer Sci. 2006;97(7):618-22. DOI: 10.1111/j.13497006.2006.00215.x

13 Rao VS, Jameel JK, Mahapatra TK, McManus PL, Fox JN, Drew PJ. Surgery is associated with lower morbidity and longer survival in elderly breast cancer patients over 80. Breast J. 2007;13(4):368-73. DOI: 10.1111/j.1524-4741.2007.00444.x

14. Tamaki Y, Miyoshi Y, Noguchi S. Adjuvant hormonal therapy. Breast Cancer. 2002;9(3):185-9. DOI: 10.1007/BF02967587

15. Thomson CS, Hole DJ, Twelves CJ, Brewster DH, Black RJ. Prognostic factors in women with breast cancer: distribution by socioeconomic status and effect on differences in survival. J Epidemiol Community Health. 2001;55(5):308-15. DOI: 10.1136/jech.55.5.308

16. Wang MC, Brookmeyer R, Jewell NP. Statistical models for prevalent cohort data. Biometrics. 1993;49(1):1-11. DOI: $10.2307 / 2532597$

17. World Health Organization. National cancer control programmes: policies and managerial guidelines. 2 . ed. Geneve; 2002. 